\title{
Panic Anxiety in Humans with Bilateral Amygdala Lesions: Pharmacological Induction via Cardiorespiratory Interoceptive Pathways
}

\author{
Sahib S. Khalsa, ${ }^{1,2,3 *}$ Justin S. Feinstein, ${ }^{1,2,5 *}$ Wei Li, ${ }^{4}$ Jamie D. Feusner, ${ }^{3}$ Ralph Adolphs, ${ }^{5}$ and Rene Hurlemann ${ }^{6}$ \\ ${ }^{1}$ Laureate Institute for Brain Research, Tulsa, Oklahoma 74136, ${ }^{2}$ Oxley College of Health Sciences, University of Tulsa, Tulsa, Oklahoma 74104, ${ }^{3}$ UCLA \\ Department of Psychiatry, Semel Institute for Neuroscience and Human Behavior, Los Angeles, California 90095, ${ }^{4}$ UCLA Neuroscience Program, Los \\ Angeles, California 90095, ${ }^{5}$ California Institute of Technology, Pasadena, California 91125, and ${ }^{6}$ Department of Psychiatry, University of Bonn, Bonn, \\ Germany
}

We previously demonstrated that carbon dioxide inhalation could induce panic anxiety in a group of rare lesion patients with focal bilateral amygdala damage. To further elucidate the amygdala-independent mechanisms leading to aversive emotional experiences, we retested two of these patients (B.G. and A.M.) to examine whether triggering palpitations and dyspnea via stimulation of nonchemosensory interoceptive channels would be sufficient to elicit panic anxiety. Participants rated their affective and sensory experiences following bolus infusions of either isoproterenol, a rapidly acting peripheral $\beta$-adrenergic agonist akin to adrenaline, or saline. Infusions were administered during two separate conditions: a panic induction and an assessment of cardiorespiratory interoception. Isoproterenol infusions induced anxiety in both patients, and full-blown panic in one (patient B.G.). Although both patients demonstrated signs of diminished awareness for cardiac sensation, patient A.M., who did not panic, reported a complete lack of awareness for dyspnea, suggestive of impaired respiratory interoception. These findings indicate that the amygdala may play a role in dynamically detecting changes in cardiorespiratory sensation. The induction of panic anxiety provides further evidence that the amygdala is not required for the conscious experience of fear induced via interoceptive sensory channels.

Key words: amygdala lesion; anxiety; emotion; heartbeat; interoception; respiration

Significance Statement

We found that monozygotic twins with focal bilateral amygdala lesions report panic anxiety in response to intravenous infusions of isoproterenol, a $\beta$-adrenergic agonist similar to adrenaline. Heightened anxiety was evident in both twins, with one twin experiencing a panic attack. The twin who did not panic displayed signs of impaired cardiorespiratory interoception, including a complete absence of dyspnea sensation. These findings highlight that the amygdala is not strictly required for the experience of panic anxiety, and suggest that neural systems beyond the amygdala are also involved. Determining these additional systems could provide key neural modulation targets for future anxiolytic treatments.

\section{Introduction}

The role of the amygdala in threat detection and the expression of anxiety and fear responses is well defined in nonhuman species

Received Nov. 15, 2015; revised Feb. 11, 2016; accepted Feb. 12, 2016.

Author contributions: S.S.K. and J.S.F. designed research; S.S.K., J.S.F., and R.H. performed research; S.S.K. and W.L. analyzed data; S.S.K., J.S.F., J.D.F., R.A., and R.H. wrote the paper.

This work was supported by NIMH 3R01MH093535-02S2, by NIH/National Center for Advancing Translational Science UCLA CTSI UL1TR000124, from the David Wilder Trust, by NARSAD Young Investigator Awards to J.S.F and S.S.K., and from the William K. Warren Foundation. We thank Courtney Sheen for assistance with participant recruitment, Nahal Sabrkhani for assistance with data collection, Larissa Portnoff for assistance with data management, Kalyanam Shivkumar, and Olujimi Ajijola for assistance with EKG review and equipment support, Belinda Houston and Bill Hirokawa for assistance with isoproterenol preparation, and Eunah Park, Regina Olivas and the entire UCLA Clinical Translational Research Center staff for assistance with protocol implementation.

The authors declare no competing financial interests. on the basis of lesion studies (Amaral and Adolphs, 2015), in addition to work in the fields of electrophysiology, optogenetics, and functional neuroimaging (LeDoux, 2000; Davis and Whalen, 2001; Oler et al., 2010; Gafford and Ressler, 2015; Tye et al., 2011). Human neuroimaging studies have demonstrated robust

\footnotetext{
*S.S.K. and J.S.F. contributed equally to this work.
}

This article is freely available online through the J Neurosci Author Open Choice option.

Correspondence should be addressed to Dr Sahib S. Khalsa, Laureate Institute for Brain Research, 6655 South Yale Avenue, Tulsa, 0K 74136-3326. E-mail: skhalsa@laureateinstitute.org.

DOI:10.1523/JNEUROSCI.4109-15.2016

Copyright $\odot 2016$ Khalsa, Feinstein et al.

This is an Open Access article distributed under the terms of the Creative Commons Attribution License Creative Commons Attribution 4.0 International, which permits unrestricted use, distribution and reproduction in any medium provided that the original work is properly attributed. 
amygdala activation in response to exteroceptive threat, with a pronounced hyperactivity observed in patients with anxiety (Büchel et al., 1999; Etkin and Wager, 2007; Davis et al., 2010; Mobbs et al., 2010). Converging evidence in humans with amygdala damage found that these patients often exhibit exteroceptive deficits in fear processing along with a reduced propensity to experience fear and post-traumatic stress (Hamann et al., 1996; Adolphs et al., 2005; Koenigs et al., 2008; Feinstein et al., 2011). It is unclear to what extent similar fear deficits extend to the interoceptive domain in humans.

Two reports of fear and panic in humans with bilateral amygdala damage suggest the amygdala may not be required for aversive visceral emotional experiences. Wiest et al. (2006) described an individual with bilateral amygdala damage due to Urbach-Wiethe Disease (UWD) who spontaneously developed recurrent panic attacks characterized by palpitations, dyspnea, and fear of dying, suggesting that anxiety circuitry beyond the amygdala generated the patient's psychopathology. In an experimental study, Feinstein et al. (2013) demonstrated that inhalation of an air mixture containing $35 \%$ carbon dioxide $\left(\mathrm{CO}_{2}\right)$ elicited panic attacks in patients with amygdala damage due to UWD, accompanied by reports of palpitations, dyspnea, dizziness, trembling, derealization, fear of dying, and escape behaviors including gasping, distressed facial expressions, and withdrawal responses.

Because $\mathrm{CO}_{2}$ has multiple actions on the peripheral nervous system and CNS - mechanoreceptive stimulation of the airways, activation of chemoreceptors in the aortic and carotid bodies, and central chemosensory effects via brainstem chemoreceptors, circumventricular and subfornical organ stimulation, and acid sensing ion channel agonism (Nattie, 1999; Ziemann et al., 2009; Colasanti et al., 2012) - it is unclear which pathways may have contributed to the observed panic responses in the prior reports. Here we aimed to determine whether induction of a subset of panic symptoms, principally palpitations and dyspnea, via a nonchemosensory peripheral pathway would be sufficient to elicit panic anxiety in the same pair of UWD patients tested previously (B.G. and A.M.).

To induce palpitations and dyspnea we selected isoproterenol, a rapid peripherally acting $\beta$-adrenergic agonist. There is a historical precedent for studying cardiorespiratory sensations in relation to emotion. This is most clearly articulated in the JamesLang theory of emotion, according to which the induction of interoceptive sensations is critical to feeling emotion (James, 1884; Lang, 1885). Likewise, classic experimental findings by Schachter and Singer (1962) demonstrated that modulation of the periphery via subcutaneous administration of adrenaline could induce emotional changes (but see Maranon, 1924; Cantril and Hunt, 1932). Here we asked whether visceral signals emitted from the body periphery can be translated into an emotional experience of fear and panic anxiety, even in individuals lacking an amygdala, a brain structure theorized to be instrumental in this translation.

Although the central amygdala has a well established visceromotor role for triggering adrenergic bodily changes in response to salient exteroceptive stimuli (Davis and Whalen, 2001), there is also a convergence of viscerosensory inputs to the basolateral amygdala (Cechetto, 1987). Thus, it is unclear to what extent the amygdala may play a role in the perception of visceral sensations (i.e., interoception).

Based on our previous research using $\mathrm{CO}_{2}$ (Feinstein et al., 2013), we predicted that isoproterenol-induced interoceptive sensations might be sufficient to elicit anxiety and panic in humans with bilateral amygdala damage. Based on our previous research using isoproterenol (Khalsa et al., 2009a), we predicted that individuals with focal bilateral amygdala damage might also demonstrate impaired cardiorespiratory interoception.

\section{Materials and Methods}

Participants received bolus intravenous infusions of either isoproterenol (a $\beta$ adrenergic agonist similar to epinephrine) or saline, and rated their affective and sensory experiences during two experimental conditions. The first consisted of a panic induction protocol using isoproterenol infusion. The second entailed assessment of cardiorespiratory interoception during isoproterenol infusion.

We chose isoproterenol for several reasons. First, its peripheral mechanism of action (Murphy and Johanson, 1985; Borges et al., 1999) provides a potent probe of afferent interoceptive processing (Khalsa et al., 2009b). Second, this approach likely bypasses chemosensory pathways stimulated by $\mathrm{CO}_{2}$ inhalation (Maddock and Carter, 1991) and lactate infusion (Liebowitz et al., 1984; Maddock et al., 2013). Third, isoproterenol has demonstrated efficacy as a panicogen (Pohl et al., 1988).

Participants were not informed of whether they were receiving saline or isoproterenol at the time of individual infusions (i.e., infusion identity was masked), though they were informed during the consent process that they would receive both at some point during the experiment. The study was approved by the Institutional Review Board of the University of California Los Angeles. All participants provided written informed consent and received compensation for their participation.

Experiment 1: panic induction. We recruited two 39-year-old monozygotic twin females with bilateral amygdala lesions due to UWD (patients B.G. and A.M.). Both patients did not meet criteria for any psychiatric disorder and were not taking any psychotropic medications at the time of evaluation, and both were otherwise physically and neurologically healthy. The neuroanatomical characteristics of their lesions as well as their case histories and neuropsychological profiles have been well characterized in a prior report (Becker et al., 2012). To further delineate the extent of their amygdala damage, high-resolution T1-weighted structural MRI scans of both twins were acquired on a 3T GE MR750 Scanner (Fig. 1). Fifteen neurologically and psychiatrically healthy female participants 


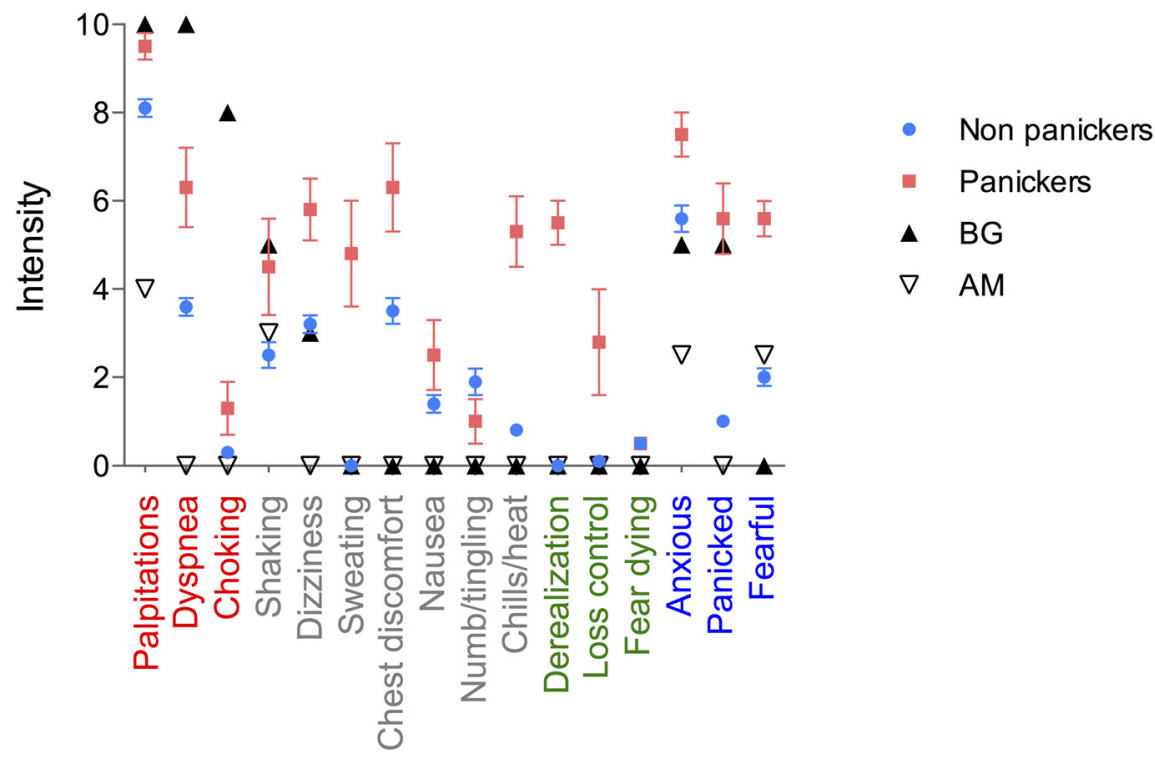

Panic symptom

Figure 2. Panic anxiety during bolus isoproterenol infusion. Participants received a $4 \mu \mathrm{g}$ bolus of isoproterenol administered in a single-blinded manner and retrospectively rated symptoms on a panic attack checklist. They were dichotomized as panickers or non-panickers according to whether they met standard criteria for a panic attack. Under these criteria, 4 of 15 comparison subjects panicked (26.7\%). One twin with bilateral amygdala lesions panicked (B.G.), whereas the other did not (A.M.). Both twins endorsed increased anxiety, as well as pal pitations and shaking during the isoproterenol infusion. One twin (B.G.) reported prominent respiratory symptoms of dyspnea and choking sensations, whereas the other reported none whatsoever (A.M.). In contrast, all of the healthy comparisons reported increased dyspnea (i.e., rated a $\geq 1$ of 10 ) at this dose. Symptoms are grouped into different colors according to category: cardiorespiratory (red), somatic (gray), cognitive (green), and emotional (blue). Error bars indicate SEM.

rically healthy female participants (mean age \pm $\mathrm{SD}=38.2 \pm 12.2$ years). Each participant received a total of 14 bolus intravenous infusions, double-blinded, in random order: seven isoproterenol infusions $(0.1,0.25,0.5,0.75,1,2$, and $4 \mu \mathrm{g})$ and seven saline infusions. Participants were instructed to rotate a dial to rate their moment-to-moment experience of the overall intensity of heartbeat and breathing sensations during each 2 min period following infusion administration. Dial ratings could range from 0 ("none or normal") to 10 ("most intense ever"). Participants were told to turn the dial $>0$ only if they noticed an increase in sensation due to the infusion; any dial turn above zero was considered a detection of isoproterenol-induced cardiorespiratory sensation. After each infusion period, participants retrospectively rated their experience of heartbeat and breathing sensations. This approach is identical to our previous studies of cardiorespiratory interoception in healthy individuals (Khalsa et al., 2009b), brain injured individuals (Khalsa et al., 2009a), and individuals with anorexia nervosa (Khalsa et al., 2015).

Apparatus and screening. Physiological data including heart rate, respiratory rate and skin conductance were continuously recorded during all infusions with a MP150 acquisition unit (Biopac Systems). All participants were screened for cardiac or respiratory disease, and all demonstrated normal physical exams and normal 12 lead electrocardiograms.

Skin conductance response. Skin conductance response (SCR) amplitudes were calculated by

(mean age $\pm \mathrm{SD}=22.3 \pm 4.5$ years) were drawn from another unpublished study with the same protocol, and their data are included simply to illustrate the efficacy of bolus isoproterenol infusions in inducing panic anxiety in a neurologically intact sample. All participants received bolus intravenous infusions in the same fixed order, single blinded, as follows: $0.1 \mu \mathrm{g} \rightarrow$ saline $\rightarrow 4 \mu \mathrm{g}$. This infusion order was selected so that the first several infusions could: (1) rule out the possibility of adverse (i.e., allergic) reactions to the isoproterenol itself, and (2) acclimatize participants to the experimental setup so that any noticeable experience of anxiety was related specifically to the experience of isoproterenol rather than anticipatory anxiety to the infusion environment in general. The $4 \mu \mathrm{g}$ bolus dose was selected to maximize the likelihood of inducing panic anxiety on the basis of: (1) safety, (2) tolerability, and (3) similar heart rate response to studies using continuous isoproterenol infusion (Nesse et al., 1984). Two minutes after receiving each infusion participants completed a panic symptom rating scale containing all 13 DSM-5 symptoms of a panic attack (Craske et al., 2010). To operationalize the experience of panic anxiety we included several variants in terminology (Adolphs, 2013; LeDoux, 2013). In addition to measuring levels of self-reported panic, we recorded levels of fear and anxiety by having participants collectively rate the terms "scared, fearful or afraid" and "anxious, tense or nervous." To avoid implicitly priming participants toward these variants, we also assessed levels of changes in other emotions, both positive and negative, that we did not expect to be altered by isoproterenol (e.g., "angry, irritated or mad," "disgusted, grossed out or repulsed," and "happy, excited or euphoric"). Each emotion and panic symptom rating could range from 0 ("not at all" or "none") to 10 ("extremely" or "most intense ever"), respectively. To define whether panic attacks had occurred during each infusion, intensity rating increases of $50 \%$ or more (i.e., $\geq 5$ point increase on the $0-10$ scale) in four or more panic symptoms were required compared with pre-infusion ratings (similar to Balon et al., 1988; Pohl et al., 1988).

Experiment 2: interoception assessment. This experiment tested patients B.G. and A.M., along with 16 sex-matched neurologically and psychiatsubtracting the minimum SCR value from the maximum value occurring during a defined $90 \mathrm{~s}$ postinfusion response window. To control for nonspecific SCRs induced by the infusion environment, SCR amplitude change was calculated by subtracting SCR amplitude for the saline infusion from the $4 \mu \mathrm{g}$ infusion. This yielded a measure of SCR change specifically due to the isoproterenol infusion. SCRs were measured from electrodes placed on the thenar and hypothenar eminence. As we have previously had difficulty obtaining SCR measures from this hand region in patient B.G. (Feinstein et al., 2013), we instead measured SCRs in this patient via electrode placement on the plantar surface of the foot (another region with concentrated eccrine sweat glands). This approach has been successfully demonstrated in other patient populations prone to developing skin changes in the hand and foot regions (Gulbandilar et al., 2008).

Interoception measures. We assessed numerous facets of interoception (Khalsa et al., 2015). We determined interoceptive detection thresholds by dichotomizing dial ratings using custom MATLAB scripts. Organspecific interoceptive symptom magnitudes were determined via retrospective baseline adjusted ratings of palpitation and dyspnea intensity. Cardiorespiratory interoceptive accuracy for each dose was indexed by zeroorder cross-correlations between mean-centered dial ratings and meancentered instantaneous heart rate changes occurring during each 2 min infusion interval. The zero-order cross-correlation compares the degree of similarity between two different waveforms as they have occurred naturally in time, thus providing an ecological and temporally valid measure of the relationship between these subjective and objective datasets.

Statistical analysis. To compare the scores of the amygdala patients with those from the comparison groups, we applied parametric analyses using $t$-tests. Two-tailed tests were used to assess the effect of isoproterenol-induced heart rate changes, and one-tailed tests were used to assess for IA deficits. We selected the corrected $t$ tests developed by John Crawford (Crawford and Garthwaite, 2002; Crawford et al., 2003) over the traditional Z-score method as they allow evaluation of a given 


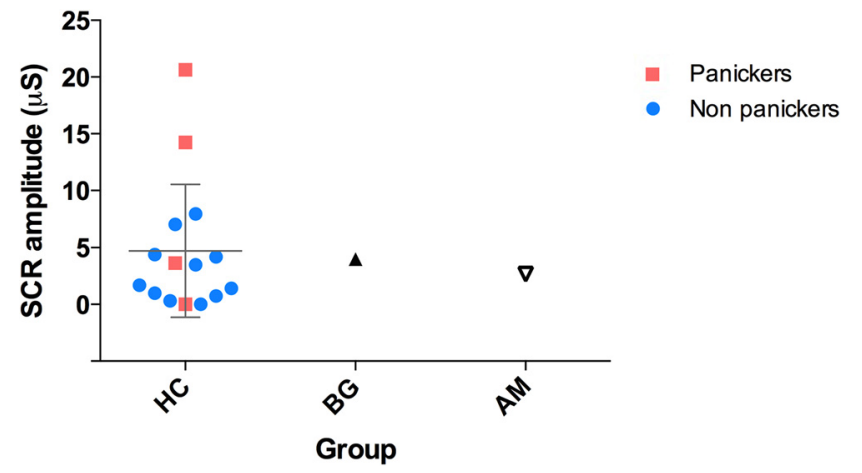

Figure 3. SCR changes during isoproterenol infusion. Both patients (B.G. and A.M.) demonstrated increased SCR amplitude changes during the $4 \mu \mathrm{g}$ bolus relative to saline. Error bars indicate $95 \%$ confidence intervals.

individual's score with modestly sized comparison samples, provide both point and 95\% confidence intervals, and are more conservative therefore lowering the rate of type I errors. Single-case comparisons of crosscorrelation coefficients were implemented using IIMA.exe software designed specifically for this purpose (Crawford et al., 2003). Single case comparisons of continuous scores were implemented using Singlims_ ES.exe (Crawford and Garthwaite, 2002).

\section{Results}

\section{Experiment 1: panic induction}

Mean heart rate responses to isoproterenol did not statistically differ between samples at the $4 \mu \mathrm{g}$ dose, for either twin (B.G.: $t_{(16)}=1.61, p=0.13$; A.M.: $\left.t_{(16)}=-0.83, p=0.42\right)$.

Figure 2 illustrates the symptoms endorsed by patients B.G. and A.M. at the $4 \mu \mathrm{g}$ dose, with respect to the healthy participants (separated by those who panicked vs those who did not). Consistent with predictions, at the $4 \mu \mathrm{g}$ dose both patients reported increases in subjective fear and anxiety. Furthermore, at the $4 \mu \mathrm{g}$ dose patient B.G. panicked, reporting prominent sensations of palpitations, dyspnea, choking, and shaking, and endorsed anxiety and feeling panicked. However, patient A.M. did not panic. She endorsed increased palpitations and shaking, and endorsed increased anxiety and feeling scared, but at a lower intensity than B.G. Additionally, in contrast with B.G.'s prominent report of dyspnea and choking sensations (10 of 10 and 8 of 10, respectively), A.M. denied experiencing any dyspnea or choking sensations whatsoever (0 of 10 for both). By comparison, 4 of 15 healthy participants panicked at the $4 \mu \mathrm{g}$ dose (26.7\%), and all participants endorsed increased dyspnea during this dose. No panic attacks occurred during any other infusion, in either sample. During the saline infusion and low-dose infusion $(0.1 \mu \mathrm{g})$, neither twin endorsed any physiological sensations or elevations in subjective fear, anxiety or panic. Across all infusions, neither twin endorsed any elevations in the other emotions assessed including happiness, anger, and disgust. Both twins demonstrated SCR amplitude changes that were within the 95\% confidence interval range of the healthy participants (Fig. 3).

\section{Experiment 2: interoception assessment}

There was no difference in mean heart rate response between either twin and the comparison sample at the $2 \mu \mathrm{g}$ dose (B.G.: $t_{(15)}=0.76, p=0.46$; A.M.: $\left.t_{(15)}=0.88, p=0.39\right)$, or at the $4 \mu \mathrm{g}$ dose (B.G.: $t_{(15)}=1.57, p=0.14$; A.M.: $t_{(15)}=1.30, p=0.21$; (Fig. 4A).

Neither amygdala lesion patient detected any cardiorespiratory interoceptive sensations below the $2 \mu \mathrm{g}$ dose, whereas the majority of the healthy comparison sample detected sensations starting at the $0.5 \mu \mathrm{g}$ dose (Fig. $4 B-D$ ). When they did detect cardiorespiratory sensations, both patients reported these to be at a lower intensity than healthy comparisons (Fig. 4B, C). For example, B.G. reported reduced palpitations and dyspnea relative to healthy comparisons, though these differences were not statistically significant [palpitations: $2 \mu \mathrm{g}\left(t_{(15)}=-0.80, p=0.22\right)$, $4 \mu \mathrm{g}\left(t_{(8)}=-1.18, p=0.14\right)$; dyspnea: $2 \mu \mathrm{g}\left(t_{(15)}=-0.56, p=\right.$ $\left.0.29), 4 \mu \mathrm{g}\left(t_{(8)}=-0.97, p=0.18\right)\right]$. In contrast, A.M. endorsed only palpitations, and at a significantly lower intensity than healthy comparisons at the highest dose $\left[2 \mu \mathrm{g}\left(t_{(15)}=-0.80, p=\right.\right.$ $\left.0.22), 4 \mu \mathrm{g}\left(t_{(8)}=-1.90, p=0.047\right)\right]$. Furthermore, she completely denied experiencing dyspnea sensations at any dose (i.e., rated as 0 of 10), including at the two highest doses. A.M.'s dyspnea rating was marginally significant at the highest dose $(2 \mu \mathrm{g}$ $\left.\left(t_{(15)}=-1.34, p=0.10\right), 4 \mu \mathrm{g}\left(t_{(8)}=-1.85, p=0.051\right)\right)$. In contrast, all of the healthy comparisons reported increased dyspnea (i.e., rated as $\geq 1$ of 10 ) at the highest two doses. Inspection of the time course of the isoproterenol-induced heart rate change and interoceptive dial ratings revealed delays in initiating ratings in both B.G. and A.M., though these were most prominent for A.M. (Fig. 4E). Furthermore, only A.M. exhibited prolonged delays in return to baseline. B.G.'s zero-order cross-correlations did not differ significantly from healthy comparisons [2 $\mu \mathrm{g}\left(t_{(15)}\right.$ $=-0.29, p=0.39)$ or $4 \mu \mathrm{g}$ dose $\left(t_{(5)}=0.86, p=0.22\right)$; Fig. $\left.3 F\right]$, whereas A.M. demonstrated a significantly lower zero-order cross-correlation at the highest dose [2 $\mu \mathrm{g}\left(t_{(15)}=-1.24, p=\right.$ $\left.0.12), 4 \mu \mathrm{g}\left(t_{(5)}=-3.9, p=0.006\right)\right]$. Figure 5 displays the complete set of time series responses for all participants.

\section{Discussion}

We found that both monozygotic twin sisters with focal bilateral amygdala damage reported increased anxiety during a panic induction challenge with bolus infusions of isoproterenol. One of the sisters (B.G.) panicked, whereas the other (A.M.) did not. This provides support for our hypothesis that isoproterenolinduced sensations are sufficient to elicit anxiety and panic in humans with bilateral amygdala damage. It also constitutes a partial replication of the finding previously reported by Feinstein et al. (2013), where both sisters reported increased anxiety, and both panicked during inhalation of a single bolus of $35 \% \mathrm{CO}_{2}$.

Several factors might explain the observation that both sisters did not panic with isoproterenol. On the one hand, the isoproterenol protocol itself may not have been a potent enough challenge. This is supported by the absence of prominent escape behaviors and by the fact that B.G.'s subjective level of panic on the visual analog scale in this study was approximately one-half of that reported previously during the $\mathrm{CO}_{2}$ challenge (Feinstein et al., 2013). Comparative studies have found that $\mathrm{CO}_{2}$ inhalation and lactate infusion typically induce higher rates of panic attacks than isoproterenol, in both healthy and anxiety disorder samples (Balon et al., 1988). The differential panicogenicity among these agents could also be explained by their differing mechanisms of action (i.e., the chemosensory stimulation specifically associated with $\mathrm{CO}_{2}$ and lactate might be an important contributor to their higher levels of panic). Thus, the lack of chemosensory pathway stimulation by isoproterenol might partly explain A.M.'s denial of dyspnea, particularly as she had previously endorsed strong dyspnea during $\mathrm{CO}_{2}$ inhalation. Even so, the fact that nonchemosensory stimulation with isoproterenol did elicit panic in B.G., and increased anxiety in both twins, provides important evidence that panic anxiety can be induced via signals emitted from the periphery of the body despite bilateral amygdala damage. 
A Heart rate response

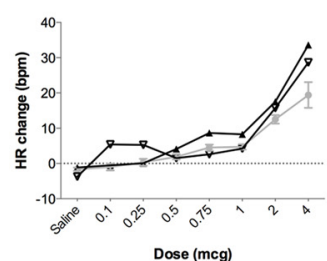

D

Interoceptive threshold

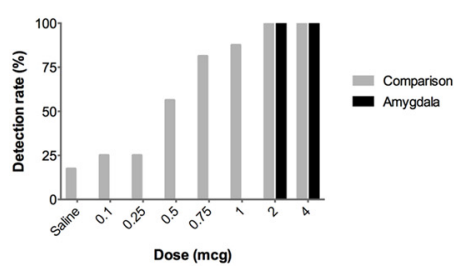

B

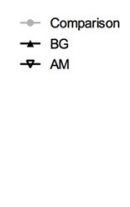

Palpitation intensity

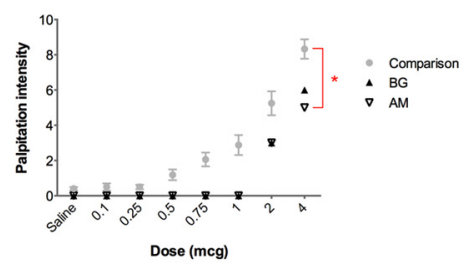

E
C

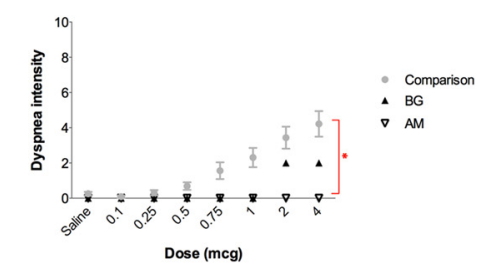

$\mathbf{F}$
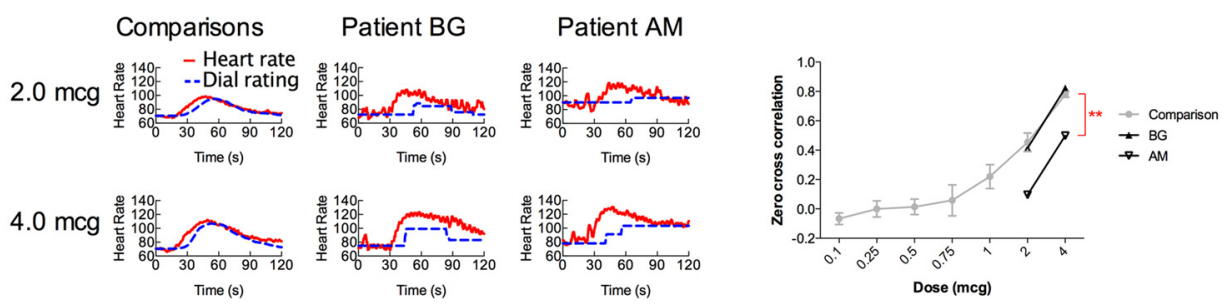

Figure 4. Cardiorespiratory interoception in humans with bilateral amygdala lesions and healthy comparisons. $\boldsymbol{A}$, Heart rate response to isoproterenol. Both patients displayed higher heart rate responses than comparisons, but these differences were not statistically significant. $\boldsymbol{B}$, Palpitation intensity. Both patients reported lower palpitation intensities. These differences were significant for patient A.M. at the highest dose ( $\left.4 \mu \mathrm{g},{ }^{*} p=0.047\right)$. C, Dyspnea intensity. Both patients reported lower dyspnea intensities. These differences were marginally significant for patient A.M. at the highest dose $\left(4 \mu \mathrm{g},{ }^{*} p=0.051\right)$. Notably, patient A.M. did not report any dyspnea across all doses, whereas all of the healthy comparisons reported increased dyspnea (i.e., rated as $\geq 1$ of 10$)$ at the highest two doses. D, Cardiorespiratory detection thresholds. Both patients detected changes only at the highest two doses ( 2 and $4 \mu \mathrm{g}$ ). $\boldsymbol{E}$, Time course of heart rate (red) and dial ratings (blue) at the two highest doses ( 2 and $4 \mu \mathrm{g}$ ). Participants rated the overall intensity of heartbeat and respiratory sensations on a moment-to-moment basis using a dial. Patient A.M. demonstrated abnormal detection latencies and prolonged dial turns. F, Cardiorespiratory accuracy, measured via zero-order cross-correlation between heart rate changes and dial ratings. Patient A.M. demonstrated significantly poorer cardiorespiratory accuracy at the highest dose (4 $\left.\mu \mathrm{g},{ }^{* *} p=0.006\right)$. Error bars indicate SEM.

Our observations of intact interoceptive fear and SCRs do not simply indicate a lack of lesion efficacy. We have demonstrated previously that these patients exhibit impaired exteroceptive fear processing in the domains of visual threat prioritization (Bach et al., 2015), impaired fear processing (Becker et al., 2012), and impoverished emotional arousal ratings (Scheele et al., 2012). Prior studies have also demonstrated that amygdala damage does not impair SCRs (Tranel and Damasio, 1989; Meadows and Kaplan, 1994), and that other brain regions such as the ventromedial prefrontal cortex, anterior cingulate and right inferior parietal cortices are implicated in deficient SCRs (Tranel and Damasio, 1994); all regions that appear completely intact in our UWD patient sample.

We also observed evidence of impaired cardiorespiratory interoception in A.M., the twin who did not panic. During isoproterenol infusions, A.M. exhibited significantly lower interoceptive accuracy as indexed via cross-correlation between heart rate changes and dial ratings. Her deficits were not simply restricted to the respiratory domain as she rated both palpitations and dyspnea sensations as less intense than healthy comparisons. Although deficits in interoceptive attention might explain A.M.'s prolonged delays in onset and offset of dial ratings, this does not fully explain her consistent and complete denial of dyspnea and choking sensations. Although we cannot completely explain this outcome, A.M.'s lack of respiratory ratings seems to suggest that her respiratory interoceptive processing pathway was impaired. Whether this would relate to a specific deficit in detecting isoproterenol-induced bronchodilation as opposed to a more general deficit in detecting changes in respiratory drive (i.e., during any homeostatic deviations) is uncertain. Testing with inspiratory breathing loads would help to differentiate these possibilities (Davenport et al., 2007). It also seems possible that A.M.'s ability to detect cardiac mechanosensory changes might be impaired on the basis of her lowered palpitation ratings. Some indirect support for this notion comes from a recent demonstra- tion that exteroceptively presented fear cues (fearful faces) presented during cardiac systole are experienced more intensely and associated with exaggerated amygdala activation (Garfinkel et al., 2014). Overall, the observation of diminished sensations in both of the patients (significant in one patient) supports our hypothesis that amygdala damage can impair cardiorespiratory interoception.

The fact that only one monozygotic twin sister panicked might be interpreted to suggest that the predisposition to panic in this twin pair was not strictly genetically determined. However, such a notion should be considered speculative: although some studies provide strong support for heritability of subjective anxiety post- $\mathrm{CO}_{2}$ inhalation as a trait marker of panic (Bellodi et al., 1998; Coryell et al., 2001; Battaglia et al., 2007; Savage et al., 2015), this relationship is not absolute (Pine et al., 2005; Terleph et al., 2006). Furthermore, the amygdala contributes less heritability influence to anxiety expression than adjacent limbic structures such as the hippocampus (Oler et al., 2010).

The current report clearly suggests that additional neural circuits beyond the amygdala must be involved in the observed fear and anxiety responses. The adjacent bed nucleus of the stria terminalis, which is not damaged in either twin, is one prominent candidate area as it has been implicated in sustained anxiety responses in humans (Alvarez et al., 2011) and animals (Duvarci et al., 2009), particularly in response to $\mathrm{CO}_{2}$ inhalation (Taugher et al., 2014). Because threat detection is adaptively tied to survival, primitive brainstem circuits (such as the retrotrapezoid nucleus, nucleus tractus solitarius, parabrachial nucleus), and hypothalamus are also likely contributors, particularly as they have key roles in sensing the internal state of the organism and have been theoretically implicated in panic anxiety (Coplan and Lydiard, 1998; Johnson et al., 2011; Guyenet and Abbott, 2013; Ruffault et al., 2015). Neuroimaging data has emerged supporting a role for the brainstem, 
Comparisons

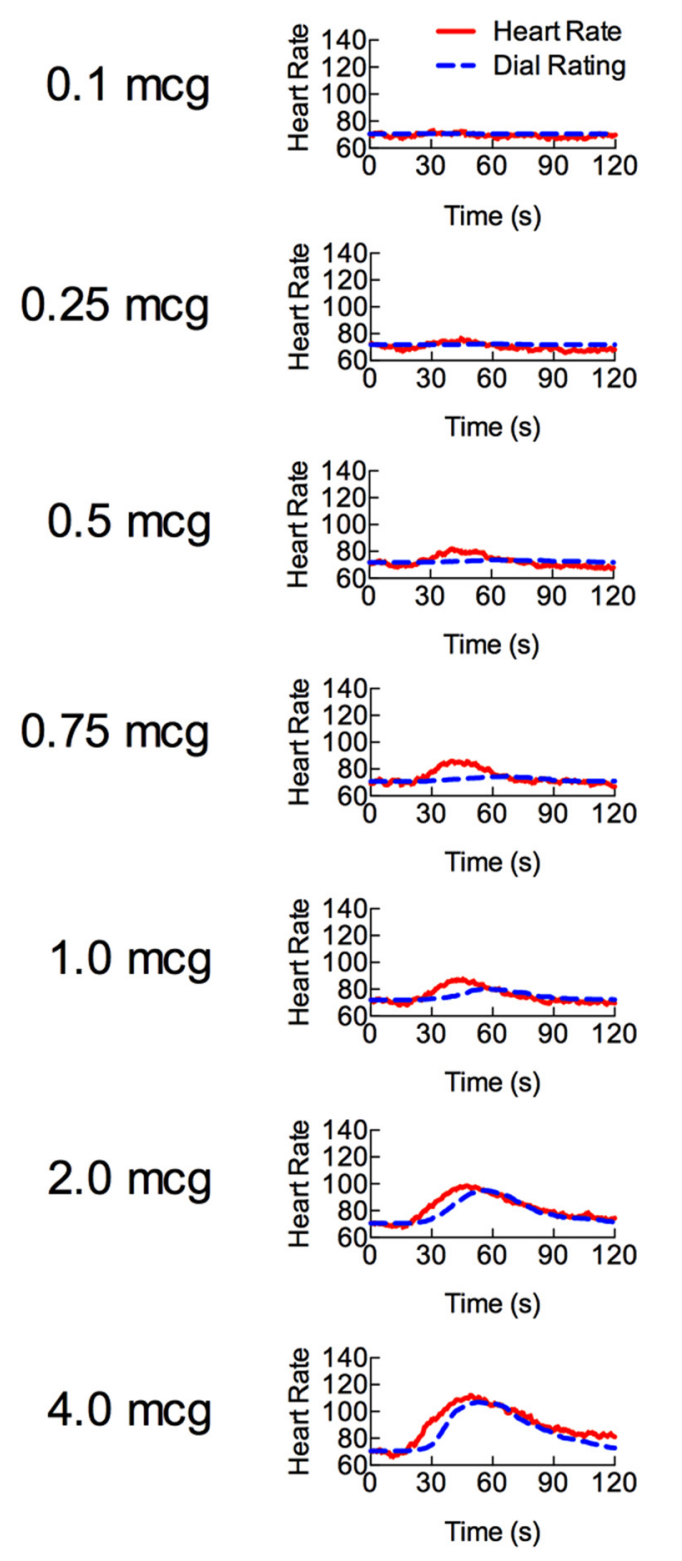

Patient BG
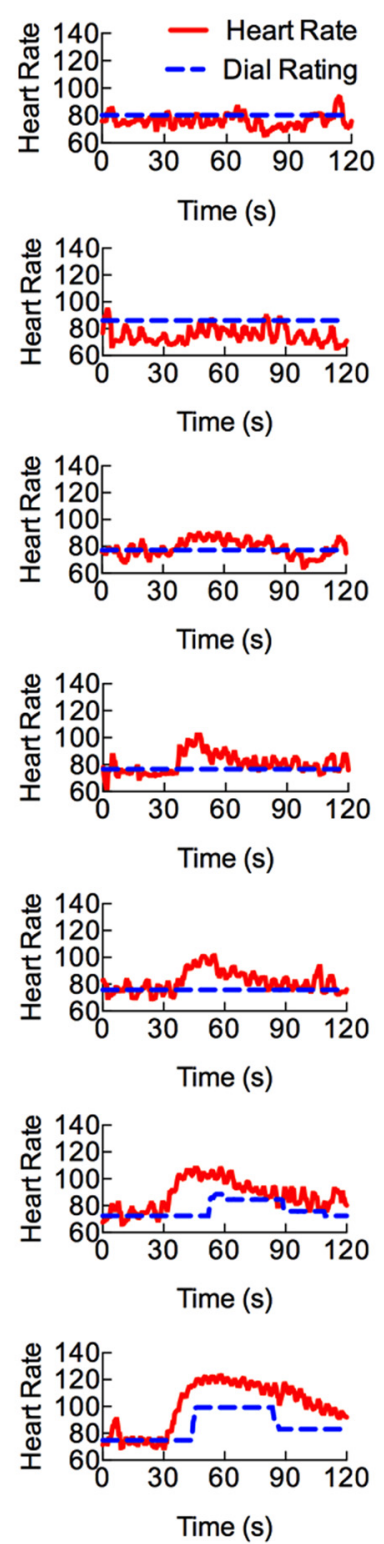

\section{Patient AM}
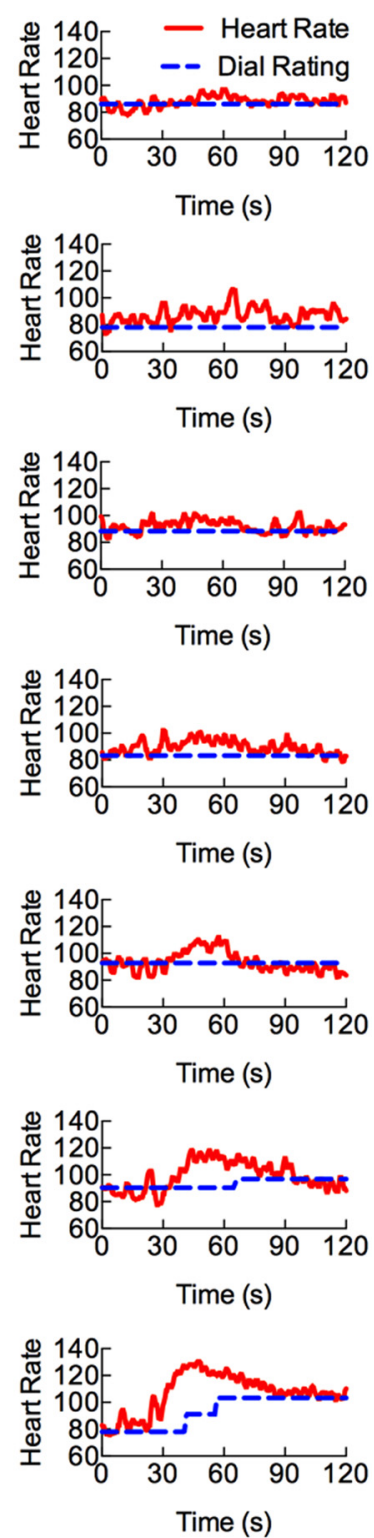

Figure 5. Time course of heart rate (red) and interoceptive dial ratings (blue) for all doses. Participants rated the overall intensity of heartbeat and respiratory sensations on a moment-to-moment basis using a dial. Both patients detected changes only at the highest two doses ( 2 and $4 \mu \mathrm{g}$ ).

diencephalon, and insula in the sensing of $\mathrm{CO}_{2}$ (Brannan et al., 2001; Pattinson et al., 2009; Goossens et al., 2014), although it is difficult to differentiate the $\mathrm{CO}_{2}$-induced vasodilation from the blood oxygenation signal. It seems unlikely that chemosensory regions, such as the organum vasculosum of the lamina terminalis or subfornical organs, played a role in the panic anxiety observed in B.G., because isoproterenol does not induce acidotic changes in the bloodstream. Converging animal and human literature suggest that these and other areas of the brain play key roles in the central sensing of $\mathrm{pH}$ changes in the blood and have relevance for panic anxiety (Shekhar and Keim, 1997; Esquivel et al., 2010; Magnotta et al., 2014). Further characterization of the respiratory pathways involved in interoceptive processing and identification of the neural circuits associated with compensatory processing of interoceptive sensations in patients with amygdala damage is warranted.
At a broader level, the current findings add to the debate posed by embodied theories of emotion, which tightly link the sensing of internal bodily signals with emotional experience. We demonstrated that visceral signals emitted from the periphery of the body can translate into emotional experience, even when the brain region that is theorized to be instrumental in this translation is compromised. Furthermore, anxiety was experienced even in the absence of an important internal sensory constituent (dyspnea) and without stimulation of chemoreceptors suggesting that other sensory pathways (e.g., cardiac) and non-sensory mechanisms (e.g., cognitive appraisal) must also play a role in generating emotion. Further studies to carefully delineate the identity and neural basis of these alternative pathways and mechanisms are needed to help to resolve this debate.

There are several limitations of this study to consider: (1) we only tested two patients with bilateral amygdala damage. Despite this small sample size, it should be emphasized that 
UWD is extremely rare with only $\sim 300$ reported cases, worldwide, since its initial discovery a century ago. (2) The amygdala lesions in these patients are largely centered on the basolateral portion of the amygdala (an area that is considered a multimodal sensory integration site that also receives viscerosensory input), with likely structural sparing in parts of the central nucleus of the amygdala (Becker et al., 2012). Although we have not previously identified any functional activity in central regions of the amygdala in these patients (Becker et al., 2012; Spunt et al., 2015), it remains possible that the intact affective responses could be attributed to potentially preserved amygdala tissue. (3) We do not know the exact onset of the amygdala lesions in these patients. The patients could therefore have exhibited impaired SCRs in the acute phase following lesion onset, with subsequent normalization of response, as observed previously in a patient following medial temporal injury due to herpes encephalitis (Asahina et al., 2003). We also do not have a premorbid assessment of either anxiety sensitivity or interoception in these patients. Therefore, we cannot preclude the possibility that these patients may have been born with an abnormal phenotype independent of their UWD. (4) An additional question relates to whether these patients may have developed compensatory rewiring of panic circuitry in response to their amygdala damage. Further testing of these patients using functional neuroimaging might help to address this issue. (5) Finally, we cannot exclude the possibility that isoproterenol could have stimulated other peripheral $\beta$-adrenergic receptors as well, such as vagal or spinal nerve afferents (Lawrence et al., 1995; Miyashita and Williams, 2006).

In summary, these findings provide further evidence that the amygdala is not essential for the experience of fear and panic anxiety. They also provide evidence that damage to the amygdala can diminish cardiorespiratory interoception.

\section{References}

Adolphs R (2013) The biology of fear. Curr Biol 23:R79-R93. CrossRef Medline

Adolphs R, Gosselin F, Buchanan TW, Tranel D, Schyns P, Damasio AR (2005) A mechanism for impaired fear recognition after amygdala damage. Nature 433:68-72. CrossRef Medline

Alvarez RP, Chen G, Bodurka J, Kaplan R, Grillon C (2011) Phasic and sustained fear in humans elicits distinct patterns of brain activity. Neuroimage 55:389-400. CrossRef Medline

Amaral DG, Adolphs R (2015) Living without an amygdala. New York: Guilford. In press.

Asahina M, Suzuki A, Mori M, Kanesaka T, Hattori T (2003) Emotional sweating response in a patient with bilateral amygdala damage. Int J Psychophysiol 47:87-93. CrossRef Medline

Bach DR, Hurlemann R, Dolan RJ (2015) Impaired threat prioritisation after selective bilateral amygdala lesions. Cortex 63:206-213. CrossRef Medline

Balon R, Pohl R, Yeragani VK, Rainey JM, Weinberg P (1988) Lactate- and isoproterenol-induced panic attacks in panic disorder patients and controls. Psychiatry Res 23:153-160. CrossRef Medline

Battaglia M, Ogliari A, Harris J, Spatola CA, Pesenti-Gritti P, ReichbornKjennerud T, Torgersen S, Kringlen E, Tambs K (2007) A genetic study of the acute anxious response to carbon dioxide stimulation in man. J Psychiatr Res 41: 906-917. CrossRef Medline

Becker B, Mihov Y, Scheele D, Kendrick KM, Feinstein JS, Matusch A, Aydin M, Reich H, Urbach H, Oros-Peusquens AM, Shah NJ, Kunz WS, Schlaepfer TE, Zilles K, Maier W, Hurlemann R (2012) Fear processing and social networking in the absence of a functional amygdala. Biol Psychiatry 72:70-77. CrossRef Medline

Bellodi L, Perna G, Caldirola D, Arancio C, Bertani A, Di Bella D (1998) CO2induced panic attacks: a twin study. Am J Psychiatry 155:1184-1188. CrossRef Medline
Borges N, Sarmento A, Azevedo I (1999) Dynamics of experimental vasogenic brain oedema in the rat: changes induced by adrenergic drugs. J Auton Pharmacol 19:209-217. CrossRef Medline

Brannan S, Liotti M, Egan G, Shade R, Madden L, Robillard R, Abplanalp B, Stofer K, Denton D, Fox PT (2001) Neuroimaging of cerebral activations and deactivations associated with hypercapnia and hunger for air. Proc Natl Acad Sci U S A 98:2029-2034. CrossRef Medline

Büchel C, Dolan RJ, Armony JL, Friston KJ (1999) Amygdala-hippocampal involvement in human aversive trace conditioning revealed through event-related functional magnetic resonance imaging. J Neurosci 19: 10869-10876. Medline

Cantril H, Hunt WA (1932) Emotional effects produced by the injection of adrenalin. Am J Psychol 44:300-307. CrossRef

Cechetto DF (1987) Central representation of visceral function. Fed Proc 46:17-23. Medline

Colasanti A, Esquivel G, Schruers KJ, Griez EJ (2012) On the psychotropic effects of carbon dioxide. Curr Pharm Des 18:5627-5637. CrossRef Medline

Coplan JD, Lydiard RB (1998) Brain circuits in panic disorder. Biol Psychiatry 44:1264-1276. CrossRef Medline

Coryell W, Fyer A, Pine D, Martinez J, Arndt S (2001) Aberrant respiratory sensitivity to $\mathrm{CO}_{2}$ as a trait of familial panic disorder. Biol Psychiatry 49:582-587. CrossRef Medline

Craske MG, Kircanski K, Epstein A, Wittchen HU, Pine DS, Lewis-Fernández R, Hinton D (2010) Panic disorder: a review of DSM-IV panic disorder and proposals for DSM-V. Depress Anxiety 27:93-112. CrossRef Medline

Crawford JR, Garthwaite PH (2002) Investigation of the single case in neuropsychology: confidence limits on the abnormality of test scores and test score differences. Neuropsychologia 40:1196-1208. CrossRef Medline

Crawford JR, Garthwaite PH, Howell DC, Venneri A (2003) Intraindividual measures of association in neuropsychology: inferential methods for comparing a single case with a control or normative sample. J Int Neuropsychol Soc 9:989-1000. CrossRef Medline

Davenport PW, Chan PY, Zhang W, Chou YL (2007) Detection threshold for inspiratory resistive loads and respiratory-related evoked potentials. J Appl Physiol 102:276-285. CrossRef Medline

Davis M, Whalen PJ (2001) The amygdala: vigilance and emotion. Mol Psychiatry 6:13-34. CrossRef Medline

Davis M, Walker DL, Miles L, Grillon C (2010) Phasic vs sustained fear in rats and humans: role of the extended amygdala in fear vs anxiety. Neuropsychopharmacology 35:105-135. CrossRef Medline

Duvarci S, Bauer EP, Paré D (2009) The bed nucleus of the stria terminalis mediates inter-individual variations in anxiety and fear. J Neurosci 29: 10357-10361. CrossRef Medline

Esquivel G, Schruers KR, Maddock RJ, Colasanti A, Griez EJ (2010) Acids in the brain: a factor in panic? J Psychopharmacol 24:639-647. CrossRef Medline

Etkin A, Wager TD (2007) Functional neuroimaging of anxiety: a metaanalysis of emotional processing in PTSD, social anxiety disorder, and specific phobia. Am J Psychiatry 164:1476-1488. CrossRef Medline

Feinstein JS, Adolphs R, Damasio A, Tranel D (2011) The human amygdala and the induction and experience of fear. Curr Biol 21:34-38. CrossRef Medline

Feinstein JS, Buzza C, Hurlemann R, Follmer RL, Dahdaleh NS, Coryell WH, Welsh MJ, Tranel D, Wemmie JA (2013) Fear and panic in humans with bilateral amygdala damage. Nat Neurosci 16:270-272. CrossRef Medline

Gafford GM, Ressler KJ (2015) Mouse models of fear-related disorders: celltype-specific manipulations in amygdala. Neuroscience. Advance online publication. CrossRef Medline

Garfinkel SN, Minati L, Gray MA, Seth AK, Dolan RJ, Critchley HD (2014) Fear from the heart: sensitivity to fear stimuli depends on individual heartbeats. J Neurosci 34:6573-6582. CrossRef Medline

Goossens L, Leibold N, Peeters R, Esquivel G, Knuts I, Backes W, Marcelis M, Hofman P, Griez E, Schruers K (2014) Brainstem response to hypercapnia: a symptom provocation study into the pathophysiology of panic disorder. J Psychopharmacol 28:449-456. CrossRef Medline

Gulbandilar E, Cimbiz A, Sari M, Ozden H (2008) Relationship between skin resistance level and static balance in type II diabetic subjects. Diabetes Res Clin Pract 82:335-339. CrossRef Medline

Guyenet PG, Abbott SB (2013) Chemoreception and asphyxia-induced arousal. Respir Physiol Neurobiol 188:333-343. CrossRef Medline 
Hamann SB, Stefanacci L, Squire LR, Adolphs R, Tranel D, Damasio H, Damasio A (1996) Recognizing facial emotion. Nature 379:497. CrossRef Medline

James W (1884) What is an emotion? Mind 9:188-205.

Johnson PL, Fitz SD, Hollis JH, Moratalla R, Lightman SL, Shekhar A, Lowry CA (2011) Induction of c-Fos in "panic/defence"-related brain circuits following brief hypercarbic gas exposure. J Psychopharmacol 25:26-36. CrossRef Medline

Khalsa SS, Rudrauf D, Feinstein JS, Tranel D (2009a) The pathways of interoceptive awareness. Nat Neurosci 12:1494-1496. CrossRef Medline

Khalsa SS, Rudrauf D, Sandesara C, Olshansky B, Tranel D (2009b) Bolus isoproterenol infusions provide a reliable method for assessing interoceptive awareness. Int J Psychophysiol 72:34-45. CrossRef Medline

Khalsa SS, Craske MG, Li W, Vangala S, Strober M, Feusner JD (2015) Altered interoceptive awareness in anorexia nervosa: effects of meal anticipation, consumption and bodily arousal. Int J Eat Disord 48:889-897. CrossRef Medline

Koenigs M, Huey ED, Raymont V, Cheon B, Solomon J, Wassermann EM, Grafman J (2008) Focal brain damage protects against post-traumatic stress disorder in combat veterans. Nat Neurosci 11:232-237. CrossRef Medline

Lang CG (1885) The mechanisms of the emotions. In: The classical psychologist: selections illustrating psychology from Anaxagoras to Wundt, pp 672-684. Boston: Houghton Mifflin.

Lawrence AJ, Watkins D, Jarrott B (1995) Visualization of betaadrenoceptor binding sites on human inferior vagal ganglia and their axonal transport along the rat vagus nerve. J Hypertens 13:631-635. CrossRef Medline

LeDoux JE (2000) Emotion circuits in the brain. Annu Rev Neurosci 23: 155-184. CrossRef Medline

LeDoux JE (2013) The slippery slope of fear. Trends Cogn Sci 17:155-156. CrossRef Medline

Liebowitz MR, Fyer AJ, Gorman JM, Dillon D, Appleby IL, Levy G, Anderson S, Levitt M, Palij M, Davies SO. (1984) Lactate provocation of panic attacks: I. Clinical and behavioral findings. Arch Gen Psychiatry 41: 764-770. CrossRef Medline

Maddock RJ, Carter CS (1991) Hyperventilation-induced panic attacks in panic disorder with agoraphobia. Biol Psychiatry 29:843-854. CrossRef Medline

Maddock RJ, Buonocore MH, Miller AR, Yoon JH, Soosman SK, Unruh AM (2013) Abnormal activity-dependent brain lactate and glutamate plus glutamine responses in panic disorder. Biol Psychiatry 73:1111-1119. CrossRef Medline

Magnotta VA, Johnson CP, Follmer R, Wemmie JA (2014) Functional t1rho imaging in panic disorder. Biol Psychiatry 75:884-891. CrossRef Medline

Maranon G (1924) Contribution a l'etude de l'action emotive de l'adrenaline. Revue Française d'Endocrinologie 2:301-325.

Meadows ME, Kaplan RF (1994) Dissociation of autonomic and subjective responses to emotional slides in right hemisphere damaged patients. Neuropsychologia 32:847-856. CrossRef Medline

Miyashita T, Williams CL (2006) Epinephrine administration increases neural impulses propagated along the vagus nerve: role of peripheral beta-adrenergic receptors. Neurobiol Learn Mem 85:116-124. CrossRef Medline

Mobbs D, Yu R, Rowe JB, Eich H, FeldmanHall O, Dalgleish T (2010) Neural activity associated with monitoring the oscillating threat value of a tarantula. Proc Natl Acad Sci U S A 107:20582-20586. CrossRef Medline

Murphy VA, Johanson CE (1985) Adrenergic-induced enhancement of brain barrier system permeability to small nonelectrolytes: choroid plexus versus cerebral capillaries. J Cereb Blood Flow Metab 5:401412. CrossRef Medline

Nattie E (1999) $\mathrm{CO}_{2}$, brainstem chemoreceptors and breathing. Prog Neurobiol 59:299-331. CrossRef Medline

Nesse RM, Cameron OG, Curtis GC, McCann DS, Huber-Smith MJ (1984)
Adrenergic function in patients with panic anxiety. Arch Gen Psychiatry 41:771-776. CrossRef Medline

Oler JA, Fox AS, Shelton SE, Rogers J, Dyer TD, Davidson RJ, Shelledy W, Oakes TR, Blangero J, Kalin NH (2010) Amygdalar and hippocampal substrates of anxious temperament differ in their heritability. Nature 466: 864-868. CrossRef Medline

Pattinson KT, Mitsis GD, Harvey AK, Jbabdi S, Dirckx S, Mayhew SD, Rogers R, Tracey I, Wise RG (2009) Determination of the human brainstem respiratory control network and its cortical connections in vivo using functional and structural imaging. Neuroimage 44:295-305. CrossRef Medline

Pine DS, Klein RG, Roberson-Nay R, Mannuzza S, Moulton JL 3rd, Woldehawariat G, Guardino M (2005) Response to 5\% carbon dioxide in children and adolescents: relationship to panic disorder in parents and anxiety disorders in subjects. Arch Gen Psychiatry 62:73-80. CrossRef Medline

Pohl R, Yeragani VK, Balon R, Rainey JM, Lycaki H, Ortiz A, Berchou R, Weinberg P (1988) Isoproterenol-induced panic attacks. Biol Psychiatry 24:891-902. CrossRef Medline

Ruffault PL, D'Autreaux F, Hayes JA, Nomaksteinsky M, Autran S, Fujiyama T, Hoshino M, Hagglund M, Kiehn O, Brunet JF, Fortin G, Goridis C (2015) The retrotrapezoid nucleus neurons expressing Atoh1 and Phox $2 \mathrm{~b}$ are essential for the respiratory response to $\mathrm{CO}_{2}$. eLife 4:e07051. CrossRef Medline

Savage JE, McMichael O, Gorlin EI, Beadel JR, Teachman B, Vladimirov VI, Hettema JM, Roberson-Nay R (2015) Validation of candidate anxiety disorder genes using a carbon dioxide challenge task. Biol Psychol 109: 61-66. CrossRef Medline

Schachter S, Singer JE (1962) Cognitive, social, and psychological determinants of emotional state. Psychol Rev 69:379-399. CrossRef Medline

Scheele D, Mihov Y, Kendrick KM, Feinstein JS, Reich H, Maier W, Hurlemann R (2012) Amygdala lesion profoundly alters altruistic punishment. Biol Psychiatry 72:e5-7. CrossRef Medline

Shekhar A, Keim SR (1997) The circumventricular organs form a potential neural pathway for lactate sensitivity: implications for panic disorder. J Neurosci 17:9726-9735. Medline

Spunt RP, Elison JT, Dufour N, Hurlemann R, Saxe R, Adolphs R (2015) Amygdala lesions do not compromise the cortical network for false-belief reasoning. Proc Natl Acad Sci U S A 112:4827-4832. CrossRef Medline

Taugher RJ, Lu Y, Wang Y, Kreple CJ, Ghobbeh A, Fan R, Sowers LP, Wemmie JA (2014) The bed nucleus of the stria terminalis is critical for anxiety-related behavior evoked by $\mathrm{CO} 2$ and acidosis. J Neurosci 34 : 10247-10255. CrossRef Medline

Terleph TA, Klein RG, Roberson-Nay R, Mannuzza S, Moulton JL 3rd, Woldehawariat G, Guardino M, Pine DS (2006) Stress responsivity and HPA axis activity in juveniles: results from a home-based $\mathrm{CO} 2$ inhalation study. Am J Psychiatry 163:738-740. CrossRef Medline

Tranel D, Damasio H (1989) Intact electrodermal skin conductance responses after bilateral amygdala damage. Neuropsychologia 27:381-390. CrossRef Medline

Tranel D, Damasio H (1994) Neuroanatomical correlates of electrodermal skin conductance responses. Psychophysiology 31:427-438. CrossRef Medline

Tye KM, Prakash R, Kim SY, Fenno LE, Grosenick L, Zarabi H, Thompson KR, Gradinaru V, Ramakrishnan C, Deisseroth K (2011) Amygdala circuitry mediating reversible and bidirectional control of anxiety. Nature 471:358-362. CrossRef Medline

Wiest G, Lehner-Baumgartner E, Baumgartner C (2006) Panic attacks in an individual with bilateral selective lesions of the amygdala. Arch Neurol 63:1798-1801. CrossRef Medline

Ziemann AE, Allen JE, Dahdaleh NS, Drebot II, Coryell MW, Wunsch AM, Lynch CM, Faraci FM, Howard MA 3rd, Welsh MJ, Wemmie JA (2009) The amygdala is a chemosensor that detects carbon dioxide and acidosis to elicit fear behavior. Cell 139:1012-1021. CrossRef Medline 